\title{
Gorges de la Haute-Dordogne
}

$n^{\circ} 2709$

\section{Angélique Marty}

\section{(2) OpenEdition}

\section{Journals}

Édition électronique

URL : http://journals.openedition.org/adlfi/5167

ISSN : 2114-0502

Éditeur

Ministère de la culture

\section{Référence électronique}

Angélique Marty, «Gorges de la Haute-Dordogne », ADLFI. Archéologie de la France - Informations [En ligne], Limousin, mis en ligne le 01 mars 2006, consulté le 03 mai 2019. URL : http:// journals.openedition.org/adlfi/5167

Ce document a été généré automatiquement le 3 mai 2019.

(c) Ministère de la Culture et de la Communication, CNRS 


\title{
Gorges de la Haute-Dordogne
}

$n^{\circ} 2709$

\author{
Angélique Marty
}

Une étude historique et documentaire a été réalisée sur le territoire de la communauté de communes des Gorges de la Haute-Dordogne. Deux problématiques ont été soulevées : les origines et l'histoire des établissements casadéens et le réseau des châteaux liés aux vicomtes de Ventadour et de Turenne. Cette étude réalisée en 2005-2006 a débuté par une recherche documentaire approfondie, de nombreux fonds d'archives publiques ont été dépouillés ainsi que des fonds privés (documents de la famille d'Ussel et de la famille de Bélinay). Le fonds dit "de Marèges" appartenant à cette dernière est inédit et aujourd'hui détruit. Toutefois, Madame Guély, présidente de la société historique et archéologique de Brive a pu transcrire l'intégralité des actes contenus dans ce fonds avant destruction. Ce fonds contient d'importants documents médiévaux (XIII ${ }^{\mathrm{e}} \mathrm{s} . \mathrm{XV}^{\mathrm{e}} \mathrm{s}$.). Outre les recherches documentaires, une prospection de terrain a été menée parallèlement pour repérer édifices, vestiges architecturaux et archéologiques.

2 La première partie de l'étude est consacrée aux édifices religieux et s'étend au-delà de l'histoire des deux prieurés casadéens de Saint-Pantaléon-de-Lapleau et de Liginiac, elle a également porté sur tous les autres lieux de culte (églises paroissiales, chapelles, prieurés, commanderie hospitalière de Sérandon) des dix communes concernées. La question des origines des paroisses a également été abordée, axée sur la paroisse-mère de Neuvic et sur l'étude des enclos paroissiaux dont certains ont été cartographiés.

L'autre volet de l'enquête a consisté à étudier le réseau des châteaux et fortifications situés en vicomté de Ventadour. Les paroisses étudiées se répartissent sur deux châtellenies : Egletons-Ventadour et Neuvic-Peyroux. D'après la documentation et les recherches sur le terrain, huit seigneuries (Anglards, Marèges, La Charlane, Unsac, la Maureille, Pèzeranges, Labrousse), implantées dans la châtellenie de Neuvic-Peyroux, ont été étudiées. La châtellenie d'Egletons-Ventadour ne contrôle que la petite paroisse de Saint-Pantaléon-de-Lapleau dans laquelle aucun site castral n'a été repéré pour l'instant. Parmi ces édifices, sept sont en ruine mais conservent quelques vestiges hors-sol, deux sont en partie conservés et encore habités, un est remanié de telle sorte que les éléments 
médiévaux ont disparu, trois sites sont détruits et non repérés, un édifice est en partie conservé et non habité.

4 La dernière partie de l'enquête a porté sur l'agglomération de Neuvic (Fig. $\mathrm{n}^{\circ} 1$ : Neuvic, $\mathrm{XIII}^{e} \mathrm{~s}$.-XVI ${ }^{e}$ s. : la ville fortifiée) , bourgade aux origines et au développement obscurs en raison du manque de sources écrites à l'époque médiévale : seule une transcription de la charte de la ville et quelques résumés d'actes épars constituent le corpus. En revanche davantage de documents apparaissent pour l'époque moderne. Aussi, l'interprétation de ces sources associée à l'étude du parcellaire et à une prospection de terrain permettent de soulever quelques hypothèses quant à l'étendue des fortifications de la ville et de ses faubourgs et de repérer les vestiges médiévaux visibles à l'extérieur et à l'intérieur des habitations.

\section{ANNEXES}

Fig. $\mathrm{n}^{\circ} 1$ : Neuvic, XIII' $\mathrm{s} .-\left.\mathrm{XV}\right|^{\mathrm{e}} \mathrm{s}$. : la ville fortifiée

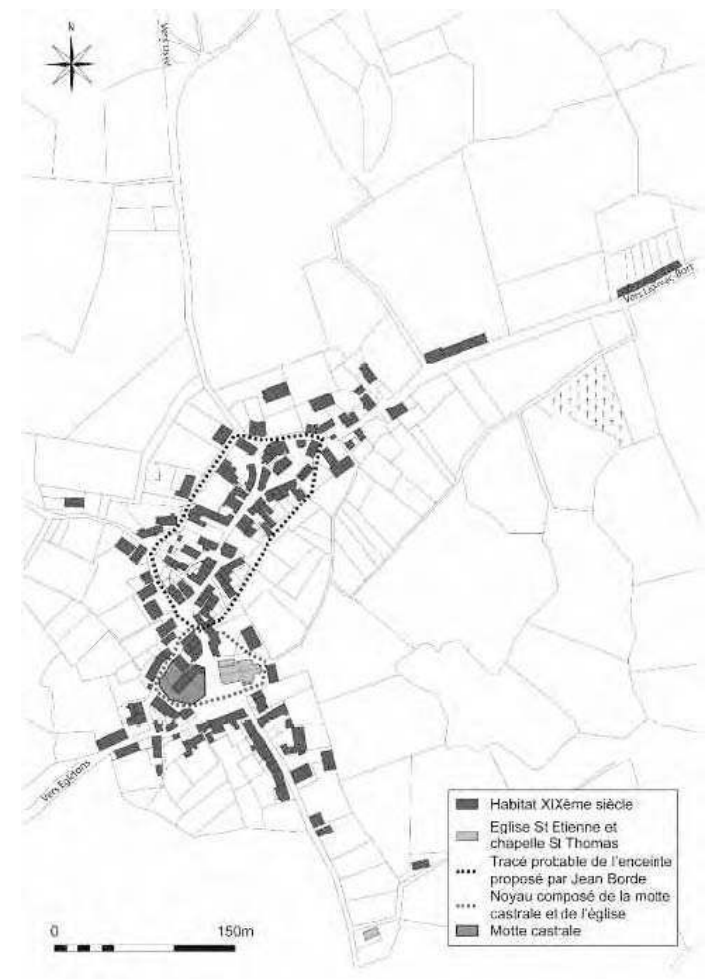

Auteur(s) : Marty, Angélique (HADÈS). Crédits : Marty, Angélique (2006) 
INDEX

operation Fouille d'évaluation (EV)

Index chronologique : Moyen Âge*, Temps Modernes

Index géographique : Limousin, Corrèze (19), Neuvic

Thèmes : archive départementale, archive municipale, archive privée, château, documentation, édifice religieux, fortification, histoire, inventaire, lieu de culte, prieuré, rivière, sources de l'histoire, sources écrites, vallée

\section{AUTEURS}

\section{ANGÉLIQUE MARTY}

HADÈS 